\title{
Biomechanical evaluation of the fixation strength of lumbar pedicle screws using cortical bone trajectory: a finite element study
}

\author{
Keitaro Matsukawa, MD, ${ }^{1}$ Yoshiyuki Yato, MD, ${ }^{2}$ Hideaki Imabayashi, MD, ${ }^{1}$ Naobumi Hosogane, MD, ${ }^{1}$ \\ Takashi Asazuma, MD, ${ }^{2}$ and Koichi Nemoto, MD' ${ }^{1}$
}

1Department of Orthopaedic Surgery, National Defense Medical College, Tokorozawa, Saitama; and 2Department of Orthopaedic Surgery, National Hospital Organization, Murayama Medical Center, Musashimurayama, Tokyo, Japan

\begin{abstract}
OBJECT Cortical bone trajectory (CBT) maximizes thread contact with the cortical bone surface and provides increased fixation strength. Even though the superior stability of axial screw fixation has been demonstrated, little is known about the biomechanical stiffness against multidirectional loading or its characteristics within a unit construct. The purpose of the present study was to quantitatively evaluate the anchorage performance of CBT by the finite element (FE) method.

METHODS Thirty FE models of L-4 vertebrae from human spines (mean age [ \pm SD] $60.9 \pm 18.7$ years, 14 men and 16 women) were computationally created and pedicle screws were placed using the traditional trajectory (TT) and CBT. The TT screw was $6.5 \mathrm{~mm}$ in diameter and $40 \mathrm{~mm}$ in length, and the CBT screw was $5.5 \mathrm{~mm}$ in diameter and $35 \mathrm{~mm}$ in length. To make a valid comparison, the same shape of screw was inserted into the same pedicle in each subject. First, the fixation strength of a single pedicle screw was compared by axial pullout and multidirectional loading tests. Next, vertebral fixation strength within a construct was examined by simulating the motions of flexion, extension, lateral bending, and axial rotation.
\end{abstract}

RESULTS CBT demonstrated a $26.4 \%$ greater mean pullout strength (POS; $p=0.003$ ) than TT, and also showed a mean $27.8 \%$ stronger stiffness $(p<0.05)$ during cephalocaudal loading and $140.2 \%$ stronger stiffness $(p<0.001)$ during mediolateral loading. The CBT construct had superior resistance to flexion and extension loading and inferior resistance to lateral bending and axial rotation. The vertebral fixation strength of the construct was significantly correlated with bone mineral density of the femoral neck and the POS of a single screw.

CONCLUSIONS CBT demonstrated superior fixation strength for each individual screw and sufficient stiffness in flexion and extension within a construct. The TT construct was superior to the CBT construct during lateral bending and axial rotation.

http://thejns.org/doi/abs/10.3171/2015.1.SPINE141103

KEY WORDS cortical bone trajectory; finite element analysis; lumbar pedicle screw; fixation strength; pullout strength; bone mineral density

$\mathrm{T}$ HE lumbar pedicle screw fixation system has become the gold standard technique for spinal fusion in the treatment of various spinal disorders. Despite the advantage of biomechanical stability using pedicle screws, screw loosening continues to occur, particularly in patients with poor bone quality, leading to loss of correction and nonunion. Achieving optimal implant fixation within osteoporotic bone presents a substantial challenge to spine surgeons. Biomechanical studies have revealed factors affecting the fixation ability of pedicle screws, such as screw mechanical properties, ${ }^{4,13}$ the anatomical characteristics of the vertebral body and pedicle, ${ }^{6,8}$ and the screw insertion technique. One optional method of enhancing the fixation strength of the screw-bone interface is

ABBREVIATIONS BMD = bone mineral density; CBT = cortical bone trajectory; DEXA = dual-energy x-ray absorptiometry; FE = finite element; POS = pullout strength; TLIF = transforaminal lumbar interbody fusion; TT = traditional trajectory.

SUBMITTED October 29, 2014. ACCEPTED January 19, 2015.

INCLUDE WHEN CITING Published online July 10, 2015; DOI: 10.3171/2015.1.SPINE141103.

DISCLOSURE The authors report no conflict of interest concerning the materials or methods used in this study or the findings specified in this paper. 
modification of the screw track, involving pilot hole size and pretapped hole size selections before screw insertion. It has been recognized that a pilot hole size smaller than the core diameter of the screw, and undertapping of a pilot hole, improve the screw pullout strength (POS). ${ }^{5,23}$

More dramatically, altering the transpedicular screw path from the traditional trajectory (TT), which follows the anatomical axis of the pedicle, is an important factor influencing screw stability. Several authors have reported that insertion of the screw vertically without convergence showed greater pullout load than a standard centered trajectory. ${ }^{11,24} \mathrm{Wu}$ et al. also investigated the stiffness of screw-bone fixation among different sagittal directions of screw placement. ${ }^{28}$ They concluded that screw insertion aimed toward the superior aspect of the vertebral body provided the best rigidity. From these studies, it has been recognized that variations in bone mineral density (BMD) within the vertebral body may have a major role in the biomechanical stiffness of the screw-bone interface.

Recently, a novel lumbar pedicle screw path named the cortical bone trajectory (CBT) was advocated by Santoni et al. in 2009.22 CBT follows a mediolaterally and caudocranially directed path through the pedicle and maximizes thread contact with the highest concentration of cortical bone. Additionally, screw insertion through a medial starting point offers advantages to avoid wide exposure of the superior facet joint and to minimize muscle dissection, providing minimal invasiveness. ${ }^{20} \mathrm{~A}$ biomechanical study of CBT revealed a $30 \%$ increase in axial pullout load compared with that for TT in the cadaveric lumbar spine. ${ }^{22}$ It has also been reported, in terms of mechanical behavior in vivo, that the insertional torque of pedicle screws using the CBT technique was $71 \%$ higher than that of the TT technique. ${ }^{19}$ Even though the superior stability of axial screw fixation using CBT has been demonstrated, little is known about the biomechanical stiffness of the screw-bone interface against multidirectional loading. Furthermore, there are some concerns about the fixation stability of CBT. CBT screws are shorter than TT screws and are inserted divergently, resulting in a short lever arm from the median axis; however, not much research has been conducted to clarify fundamental characteristics of CBT within a screw-vertebra construct. The objective of the present study was to quantitatively evaluate CBT screw stability by the finite element (FE) method and to elucidate its advantages and drawbacks.

\section{Methods}

The CT scans of 30 patients were selected to include a range of ages and values of BMD. These patients included 14 men and 16 women, with a mean age ( \pm SD) of $60.9 \pm$ 18.7 years (range $24-88$ years), who underwent surgery for degenerative spinal disorders. Patients who had previously undergone surgery or were diagnosed with vertebral malformation or metastases were excluded. In each case, a CT scan was taken with a slice thickness of $1 \mathrm{~mm}$, and BMD in the femoral neck and lumbar spine was measured by dual-energy x-ray absorptiometry (DEXA) before the surgery. The study received ethics committee approval from the National Defense Medical College and all patients provided signed informed consent.

\section{Finite Element Models}

Three-dimensional FE models of L-4 vertebrae were constructed from the patients' CT data using Mechanical Finder software (version 6.2, extended edition; Research Center of Computational Mechanics). The models were divided into $0.5-1-\mathrm{mm}$ tetrahedral solid elements with $150,000-200,000$ nodes and 800,000-1,000,000 solid elements. To obtain the geometrical data of the vertebra, the BMD of each element was computed from the Hounsfield unit values in CT. Also, Young's modulus and the yield stress of each element were employed from a previous study by Keyak et al., ${ }^{12}$ and Poisson's ratio of each element was set as 0.4 . Then, each vertebra was implanted with a pedicle screw (SOLERA Spinal System; Medtronic) that is designed with cortical thread at the proximal shaft and cancellous thread at the screw tip. The FE models of the pedicle screw were developed from micro-CT data and were also divided into $0.5-1-\mathrm{mm}$ tetrahedral solid elements. These screws were assumed to have the material properties of cobalt chromium alloy with Young's modulus of $220 \mathrm{GPa}$, yield stress of $900 \mathrm{MPa}$, and Poisson's ratio of $0.33,{ }^{18}$ which is the same properties as the SOLERA Spinal System. The screw-bone interface was modeled using surface-to-surface contact (not bonded) condition and the friction coefficient was determined to be zero, based on a previous study. ${ }^{4}$ The computer solution time per analysis ranged from 24 to 52 hours, and a total of 540 biomechanical analyses using the L-4 vertebrae of 30 individuals were performed.

\section{Insertional Trajectory}

We compared the TT and CBT for each lumbar vertebra (Fig. 1). TT screws were inserted into the vertebral body along an anatomical axis of the pedicle and parallel to the vertebral endplate, using Weinstein's technique. ${ }^{27}$ According to our previous morphometric study, the starting point for CBT was located at the lateral aspect of the pars interarticularis projecting in the 5 o'clock orientation in the left pedicle and the 7 o'clock orientation in the right

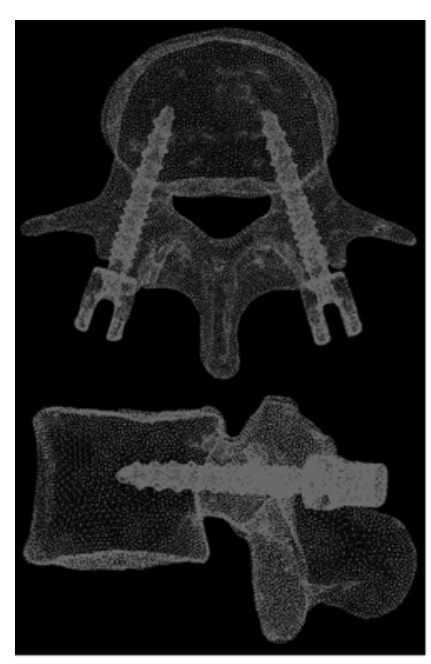

Traditional Trajectory

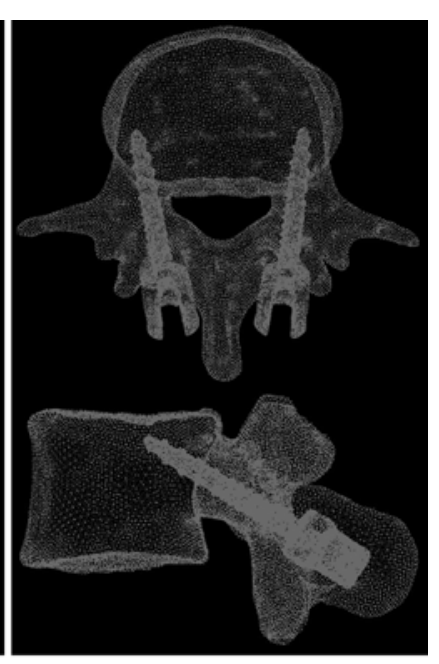

Cortical Bone Trajectory
FIG. 1. Finite element models of L-4 vertebrae with screws, showing examples of the 2 trajectories tested. 
pedicle, using the face of a clock for orientation. ${ }^{20} \mathrm{CBT}$ screws were inserted $10^{\circ}$ laterally in the axial plane and $25^{\circ}$ cranially in the sagittal plane. To achieve a simulation resembling a clinical situation, the TT screw was $6.5 \mathrm{~mm}$ in diameter and $40 \mathrm{~mm}$ in length, and the CBT screw was $5.5 \mathrm{~mm}$ in diameter and $35 \mathrm{~mm}$ in length. ${ }^{19}$ Each screw was carefully placed in the appropriate position to prevent any cortical breaching and bicortical purchase into the anterior vertebral body because these two conditions may potentially influence screw fixation values.

\section{Comparison of Single Pedicle Screw Fixation Strength}

In each model, nonlinear FE analysis was performed. An incremental loading rate of $20 \mathrm{~N} / \mathrm{step}$ was applied to the screw head, and the construction was full fixation in all directions at the surface of the superior and inferior vertebral endplates. Under loading conditions in the axis of the screw, the POS was defined as the load of a flexion point on a load-displacement curve just before an abrupt increase in displacement (Fig. 2). Next, to evaluate the fixation strength of the screw-bone interface against multidirectional loading, up to $200 \mathrm{~N}$ loads were applied in the cranial, caudal, medial, and lateral directions perpendicular to the anteroposterior vertebral axis, and then screw stiffness was examined (Fig. 3A).

\section{Comparison of Vertebral Fixation Strength Within a Construct}

Each vertebra was implanted with paired pedicle screws using the TT and CBT techniques. The construction involved full fixation at the bilateral screw heads, and a loading rate of $20 \mathrm{~N} / \mathrm{step}$ was gradually applied to the vertebral body to induce each plane of motion, such as flexion, extension, lateral bending, and axial rotation (Fig. 3B). Under destructive loading, the ultimate failure loads were determined from the load-displacement curve and defined as the load of a flexion point before a clear increase of the curve.

\section{Statistical Methods}

Results are presented as means \pm standard deviations.

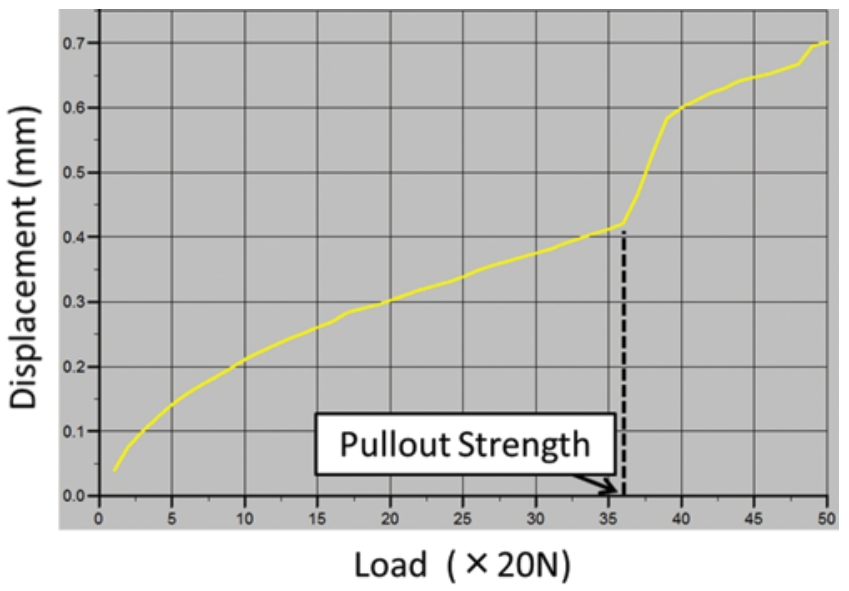

FIG. 2. A typical load-displacement curve illustrating POS. Figure is available in color online only.
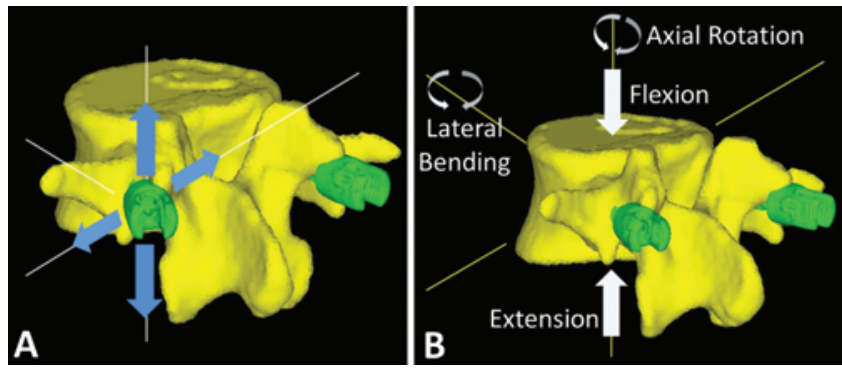

FIG. 3. Illustration of loading conditions. A: Multidirectional loading to a single screw. B: Loading conditions for flexion/extension, lateral bending, and axial rotation. Figure is available in color online only.

Data were compared using paired t-tests. Pearson's correlation coefficient was used to analyze how screw fixation strength changes with BMD. Significance was defined as $\mathrm{p}<0.05$.

\section{Results}

\section{Comparison of Single Pedicle Screw Fixation Strength}

The mean POSs of TT and CBT screws were $1141 \pm$ $330 \mathrm{~N}$ and $1376 \pm 254 \mathrm{~N}$, respectively (Fig. 4). CBT demonstrated a $26.4 \%$ higher mean POS, which was statistically significant $(\mathrm{p}=0.003)$. The correlation coefficient between the POS and BMD of the femoral neck (TT: $r=$ $0.84, p<0.001$; CBT: $r=0.75, p<0.001$ ) was significantly higher than the mean BMD of all the lumbar vertebrae (TT: $r=0.58, p<0.001 ;$ CBT: $r=0.50, p=0.005$ ) and the BMD of L-4 vertebrae (TT: $r=0.49, p=0.005$; CBT: $r=$ $0.38, \mathrm{p}=0.03$; Fig. 5).

In terms of the multidirectional loading, medial/lateral stiffness was greater than cranial/caudal stiffness in both trajectories (Fig. 6). CBT demonstrated a mean 22\% stronger stiffness in cranial load (TT: $1114 \pm 558 \mathrm{~N} / \mathrm{mm}$; CBT: $1246 \pm 566 \mathrm{~N} / \mathrm{mm} ; \mathrm{p}=0.36), 33.7 \%$ stronger stiffness in caudal load (TT: $1055 \pm 529 \mathrm{~N} / \mathrm{mm}$; CBT: 1321 $\pm 580 \mathrm{~N} / \mathrm{mm} ; \mathrm{p}=0.06), 146 \%$ stronger stiffness in medial load (TT: $1550 \pm 930 \mathrm{~N} / \mathrm{mm}$; CBT: $3500 \pm 1697 \mathrm{~N} /$ $\mathrm{mm} ; \mathrm{p}<0.001$ ), and $134.5 \%$ stronger stiffness in lateral load (TT: $1464 \pm 934 \mathrm{~N} / \mathrm{mm}$; CBT: $3065 \pm 1450 \mathrm{~N} / \mathrm{mm}$; $\mathrm{p}<0.001)$ compared with the TT. Among different BMD

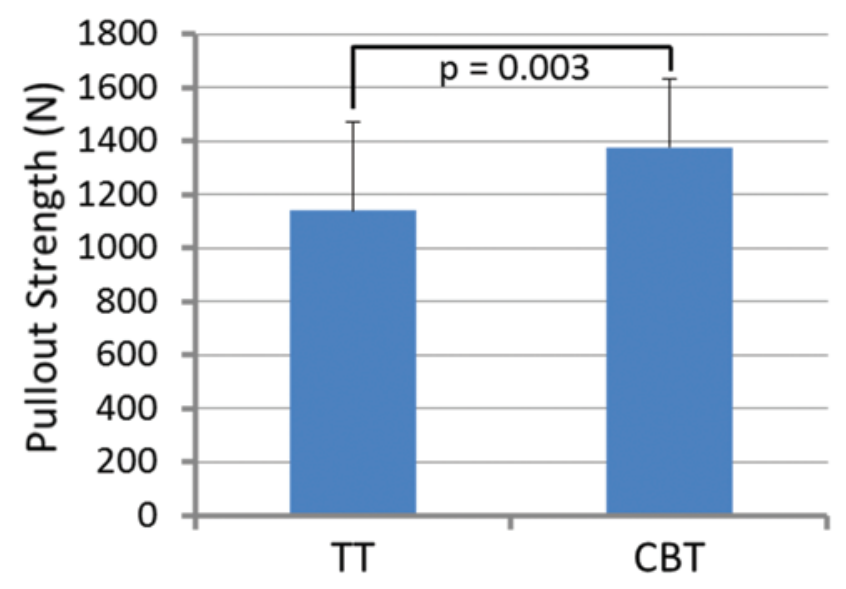

FIG. 4. Bar graph showing CBT demonstrated significantly higher POS than TT. Figure is available in color online only. 


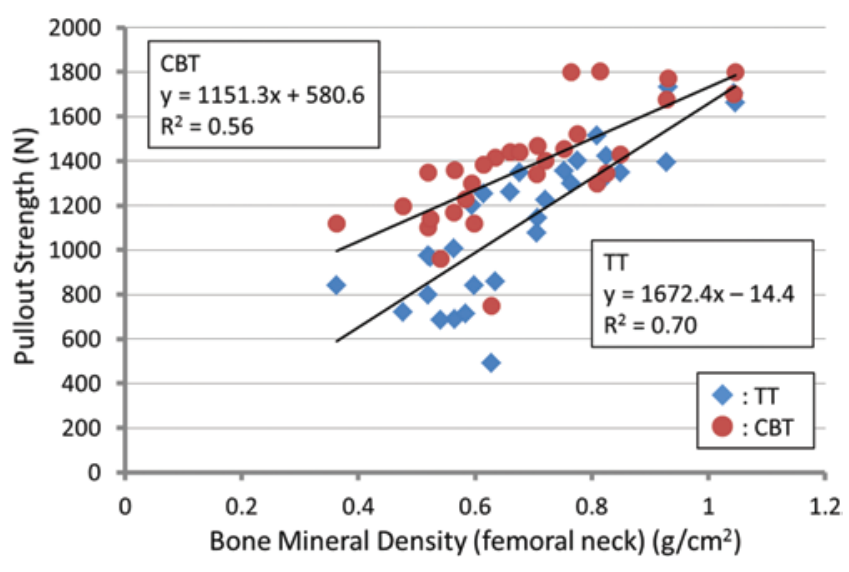

FIG. 5. Scatterplot comparing the POS between TT and CBT screws. The superiority of CBT screws regardless of BMD values is revealed. Figure is available in color online only.

parameters, BMD of the femoral neck had the strongest correlation with all fixation stiffness (Fig. 7). Similarly, significant correlations were shown between the POS and multiaxial fixation stiffness for both trajectories (Table 1).

\section{Comparison of Vertebral Fixation Strength Within a Construct}

The CBT construct showed a mean $51 \%$ greater stiffness than the TT construct in flexion load (TT: $672 \pm 204$ $\mathrm{N} / \mathrm{mm}, \mathrm{CBT}: 989 \pm 411 \mathrm{~N} / \mathrm{mm} ; \mathrm{p}<0.001)$ and $35 \%$ higher in extension load (TT: $659 \pm 176 \mathrm{~N} / \mathrm{mm}$, CBT: $866 \pm 273$ $\mathrm{N} / \mathrm{mm}$; p < 0.001; Fig. 8, Table 2). In lateral bending load, CBT demonstrated a mean $19.6 \%$ lower stiffness (TT: $2621 \pm 1206 \mathrm{~N} / \mathrm{mm}$, CBT: $2049 \pm 936 \mathrm{~N} / \mathrm{mm} ; \mathrm{p}=0.04)$, and $37.3 \%$ lower in axial rotation (TT: $4960 \pm 2443 \mathrm{~N} /$ mm, CBT: $2846 \pm 1493 \mathrm{~N} / \mathrm{mm}$; p < 0.001). Positive linear correlations between vertebral fixation strength and BMD of the femoral neck were found in both techniques (Fig. 9, Table 3). Vertebral fixation strength was also significantly correlated with each POS for both trajectories.

\section{Discussion}

Multiple studies have been conducted to examine stability characteristics of pedicle screw systems using polyurethane foams, ${ }^{4,5,13}$ animal spines, ${ }^{16,23}$ and human cadaveric spines. Although polyurethane foams have mechanical properties simulating human cancellous bone and offer the advantages of homogeneity and reproducibility, it is difficult to replicate the complex and 3D structure of the pedicle-

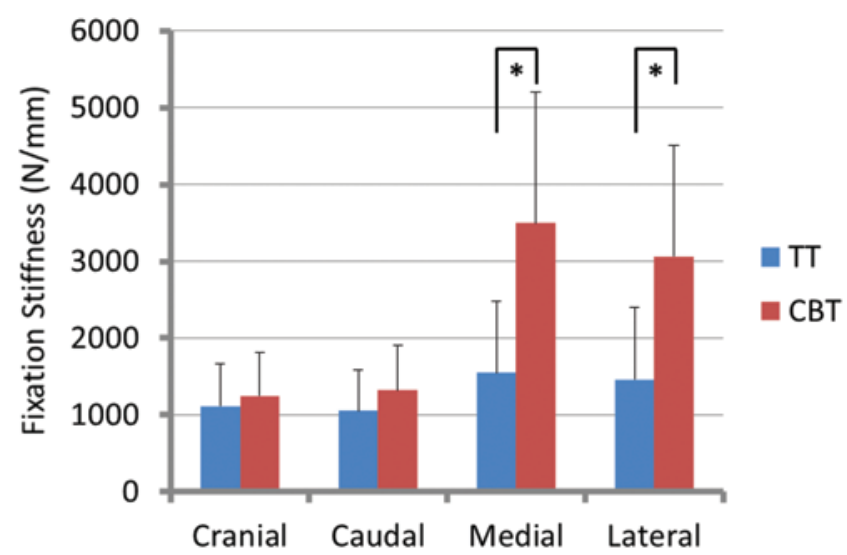

FIG. 6. Bar graph of fixation stiffness in multidirectional loading. CBT was superior to TT in each loading. ${ }^{*} p<0.001$. Figure is available in color online only.

vertebral body. ${ }^{13}$ While animal models are useful in terms of sample size and may closely represent the mechanical and physiological human clinical situations, animal spines differ from human spines in terms of morphometric features such as vertebral geometry and the size and shape of the pedicle. ${ }^{16}$ Therefore, the use of cadaveric spines is ideal to reflect human biomechanical and morphological conditions, and a lot of studies using cadaveric spines have provided significant knowledge about the biomechanical behavior of the screw-bone interface. However, there are some limitations that affect the validity of comparisons and cause biased study results, including wide individual variation of cadaveric bone quality and age, insufficient sample size, and reproducibility. To prevent such bias, we used the FE method to minimize sample variation for a fair comparison between the TT and CBT techniques. In addition to constructing a detailed geometrical structure of the vertebra, the FE method is a convenient and reproducible way of testing and reduces the expense, time, and effort of repeated mechanical tests. ${ }^{4,10}$

Santoni et al. reported that CBT screws (average 4.5$\mathrm{mm}$ diameter and 29-mm length) demonstrated 30\% greater uniaxial POS than TT screws (average 6.5-mm diameter and 51-mm length) using osteoporotic cadaveric lumbar spines (mean age 80.8 years). ${ }^{22}$ Our results are compatible with their report and reveal that CBT screws (5.5- $\mathrm{mm}$ diameter and 35-mm length) had an average of $26.4 \%$ higher POS than TT screws $(6.5-\mathrm{mm}$ diameter and 40-mm length) overall. Moreover, it was also demonstrated that the superiority of CBT in axial pullout loading var-

TABLE 1. Correlation coefficients of single-screw fixation strength in 4 types of loads

\begin{tabular}{|c|c|c|c|c|c|c|c|c|}
\hline \multirow[b]{2}{*}{ Variable } & \multicolumn{2}{|c|}{ Cranial } & \multicolumn{2}{|c|}{ Caudal } & \multicolumn{2}{|c|}{ Medial } & \multicolumn{2}{|c|}{ Lateral } \\
\hline & TT & CBT & TT & CBT & TT & CBT & TT & CBT \\
\hline \multicolumn{9}{|l|}{ BMD } \\
\hline Femoral neck & 0.77 & 0.68 & 0.75 & 0.77 & 0.66 & 0.60 & 0.68 & 0.62 \\
\hline Lumbar & 0.50 & 0.56 & 0.51 & 0.60 & 0.53 & 0.53 & 0.53 & 0.54 \\
\hline$L-4$ & 0.39 & 0.45 & 0.40 & 0.47 & 0.50 & 0.48 & 0.48 & 0.52 \\
\hline POS & 0.80 & 0.68 & 0.78 & 0.71 & 0.62 & 0.39 & 0.65 & 0.42 \\
\hline
\end{tabular}



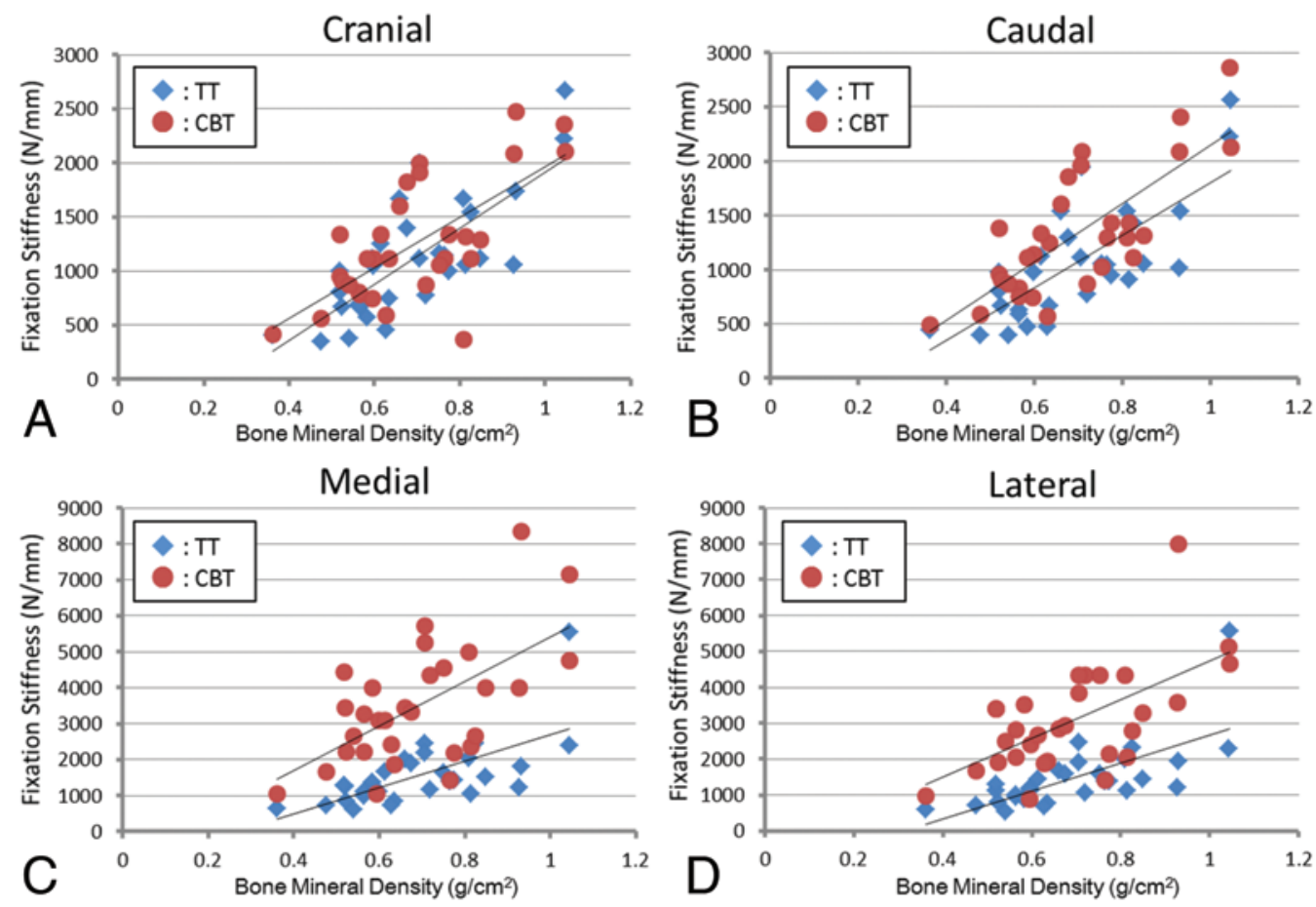

FIG. 7. Scatterplots showing positive linear correlations between BMD of the femoral neck and stiffness for each type of loading. Figure is available in color online only.

ied with BMD (Fig. 5). Eleven of 30 subjects with femoral neck BMD of less than $0.6 \mathrm{~g} / \mathrm{cm}^{2}$ (mean age 71.9 years) demonstrated a $42.3 \%$ increase, while 8 of 30 subjects with femoral neck BMD of more than $0.8 \mathrm{~g} / \mathrm{cm}^{2}$ (mean age 49.2 years) demonstrated only a $6.9 \%$ increase. There was an increase in the CBT superiority with decreasing BMD. This difference may be explained by the fact that CBT screws anchored mainly in cortical bone are less influenced by the osteoporotic process than TT screws in cancellous bone. ${ }^{19}$

With respect to the screw stability against multidirectional loading, Santoni et al. reported equivalent toggle

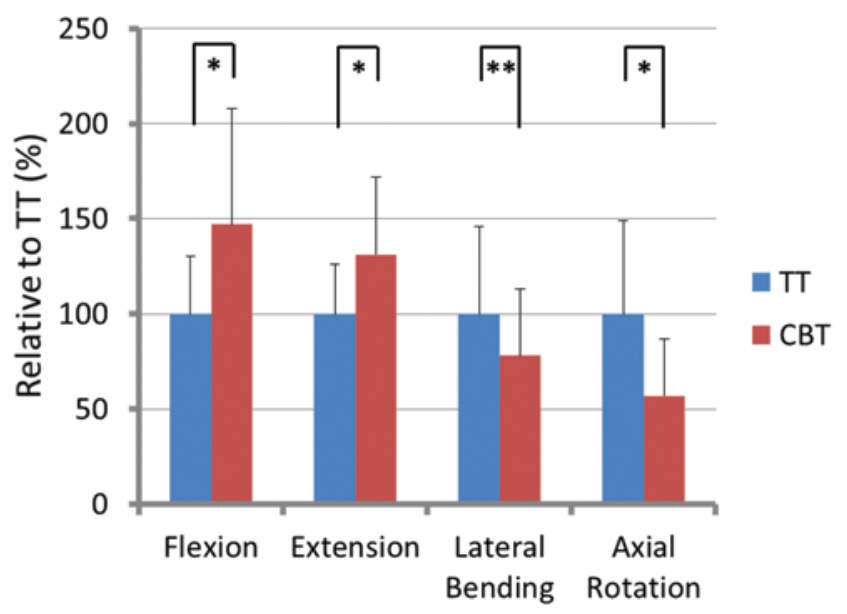

FIG. 8. Bar graph demonstrating that the CBT construct shows greater stiffness during flexion and extension loading and lower stiffness during lateral bending and axial rotation. The TT construct stiffness was given a value of $100 \%$ for each type of motion. ${ }^{*} p<0.001,{ }^{* *} p<0.05$. Figure is available in color online only. characteristics of CBT compared with $\mathrm{TT} .{ }^{22}$ Contrary to this result, our study showed favorable strength of CBT, with an average of $27.8 \%$ stronger stiffness in cephalocaudal loadings $(p<0.05)$ and $140.2 \%$ stronger in mediolateral loadings ( $p<0.001)$. Two factors appeared to cause these differences. One factor is that our testing involved noncyclic loading, and the other is that we used larger CBT screws with 5.5-mm diameters to achieve effective matching of the pedicle width and obtain more thread contact with cortical bone. Zindrick et al. showed that increases in the outer diameter of a screw enhance the fixation stability, ${ }^{30}$ and Hirano et al. also concluded that the cortical fitness within the pedicle is essential for screw stability. ${ }^{9}$

Lastly, vertebral fixation strength was examined using the paired-screw vertebral model. CBT had superior resistance to flexion/extension loading and inferior resistance to lateral bending/axial rotation. Regardless of BMD, these trends were universally identified, especially in axial rotation, and it appeared that the divergent and short lever arm construct of CBT was associated with this result. Our results are consistent with recent findings by Perez-Orribo et al., who undertook a biomechanical comparative study between CBT and TT screw-rod constructs using human cadaveric spines. ${ }^{21}$ According to their report, the CBT construct provided almost the same stability as the TT construct; however, when the intervertebral disc was left intact or a transforaminal lumbar interbody fusion (TLIF) implant was used, significantly greater stiffness was observed with the use of TT during lateral bending and axial rotation. We recommend the TT rather than the CBT in cases that require bilateral total facetectomy, which makes the lumbar spine very unstable, especially in lateral bending and axial rotation. ${ }^{1,29}$ 
TABLE 2. Summary of load to failure data in 4 types of motion*

\begin{tabular}{|c|c|c|c|c|c|c|c|c|}
\hline \multirow[b]{2}{*}{ Variable } & \multicolumn{2}{|c|}{ Flexion } & \multicolumn{2}{|c|}{ Extension } & \multicolumn{2}{|c|}{ Lateral Bending } & \multicolumn{2}{|c|}{ Axial Rotation } \\
\hline & TT & CBT & TT & CBT & TT & CBT & TT & CBT \\
\hline Ultimate load $(\mathrm{N})$ & $402 \pm 51$ & $555 \pm 125$ & $381 \pm 46$ & $532 \pm 103$ & $703 \pm 167$ & $679 \pm 150$ & $1950 \pm 436$ & $1071 \pm 227$ \\
\hline Displacement (mm) & $0.63 \pm 0.13$ & $0.62 \pm 0.17$ & $0.60 \pm 0.10$ & $0.64 \pm 0.11$ & $0.29 \pm 0.08$ & $0.38 \pm 0.12$ & $0.46 \pm 0.17$ & $0.43 \pm 0.14$ \\
\hline Stiffness (N/mm) & $672 \pm 204$ & $989 \pm 411$ & $659 \pm 176$ & $866 \pm 273$ & $2621 \pm 1206$ & $2049 \pm 936$ & $4960 \pm 2443$ & $2846 \pm 1493$ \\
\hline
\end{tabular}

${ }^{*}$ All data given as means \pm SDs.

Several investigators have emphasized the importance of BMD for screw fixation strength. ${ }^{6,8}$ The current results confirm the same effect of BMD. Interestingly, the correlation coefficient of the femoral neck BMD was the highest among the 3 types of BMD parameters. This occurred because the presence of osteophyte formation, articular facet hypertrophy, and soft-tissue degeneration such as aortic calcification could influence the lumbar BMD data by DEXA, leading to overestimation of its true value. ${ }^{3}$ What is particularly remarkable is that the POS of a single screw also contributed to the vertebral fixation strength of the construct.

From these biomechanical points of view mentioned above, we recommend two basic points to achieve better mechanical stability and high fusion rates using the CBT technique. One point is enhancing each screw's fixation within a construct. CBT is not only a transpedicular trajectory directed laterally, but also an exceptional trajectory engaging with denser cortical bone to the maximum extent. To obtain the best fixation strength, future elucidation of the optimal screw size and the ideal trajectory for CBT is needed. ${ }^{20}$ The other point is to take countermeasures against torsional motion on the whole construct. The addition of crosslinks is one strategy, and previous studies
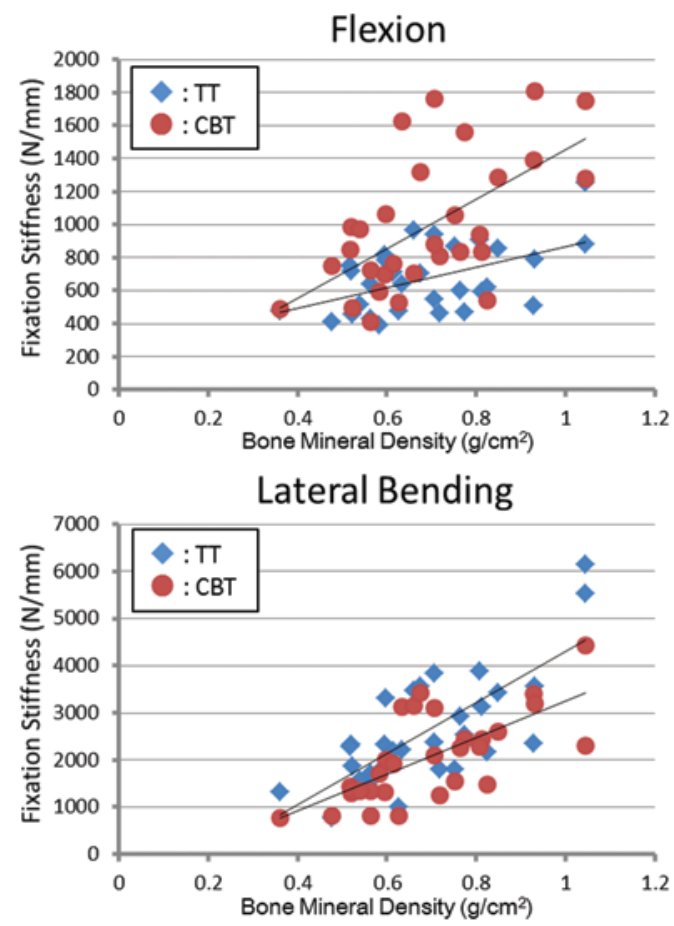

have shown increased stiffness in lateral bending and axial rotation upon such an addition. ${ }^{2,17,26}$ In addition, construct stiffness is also dependent on the grade of facetectomy, ${ }^{1,29}$ and the type, size, and orientation of the intervertebral cage. $7,14,25$ Tsitsopoulos et al. performed a biomechanical analysis on a lumbar interbody fusion technique using cadaveric spines, and concluded that the greater stability of the TLIF construct was due to more anterior placement of the cage and preservation of the contralateral facet joint. ${ }^{25}$ Placement of a large interbody cage anteriorly and preservation of posterior elements should be considered for enhancing construct stiffness.

There are some limitations to this study that should be mentioned. The FE method in our study is difficult to reproduce clinical preparation techniques for screw insertion, such as pilot hole size and pretapping hole size. The screw path of CBT is usually prepared using the same size tap as the planned screw to reduce the risk of cortical bone fissures during screw placement, while the screw path of TT is prepared using a tapping size smaller than the screw diameter. ${ }^{19}$ These factors play important roles in pedicle screw fixation and may be topics of further consideration. ${ }^{5,23} \mathrm{~A}$ second limitation is that we used FE models of single segments of the vertebra. The multiple segment and
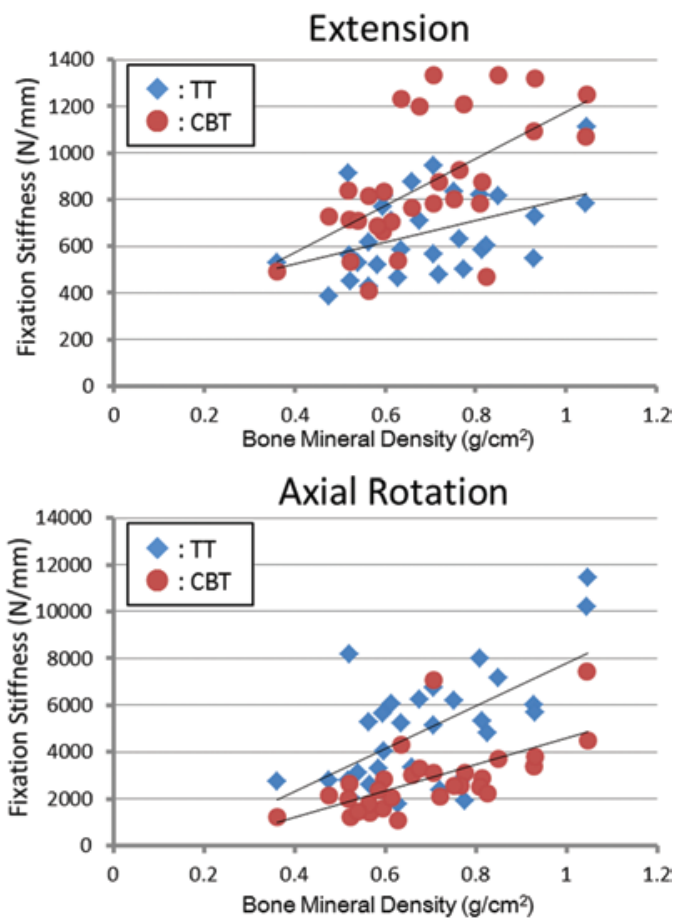

FIG. 9. Scatterplots showing positive linear correlations between BMD of the femoral neck and stiffness for each type of motion. Figure is available in color online only. 
TABLE 3. Correlation coefficient of vertebral fixation strength in 4 types of motion

\begin{tabular}{|c|c|c|c|c|c|c|c|c|}
\hline \multirow[b]{2}{*}{ Variable } & \multicolumn{2}{|c|}{ Flexion } & \multicolumn{2}{|c|}{ Extension } & \multicolumn{2}{|c|}{ Lateral Bending } & \multicolumn{2}{|c|}{ Axial Rotation } \\
\hline & TT & CBT & TT & CBT & TT & CBT & TT & CBT \\
\hline \multicolumn{9}{|l|}{ BMD } \\
\hline Femoral neck & 0.50 & 0.60 & 0.44 & 0.61 & 0.74 & 0.69 & 0.62 & 0.63 \\
\hline Lumbar & 0.21 & 0.55 & 0.14 & 0.51 & 0.51 & 0.47 & 0.44 & 0.59 \\
\hline L-4 & 0.14 & 0.43 & 0.06 & 0.38 & 0.39 & 0.31 & 0.41 & 0.45 \\
\hline POS & 0.59 & 0.55 & 0.51 & 0.62 & 0.73 & 0.67 & 0.64 & 0.57 \\
\hline
\end{tabular}

screw-rod construct model provides a better representation of the actual situation. However, the inclusion of a motion segment requires more complex information on material properties and geometry of the intervertebral elements, leading to more complicated results. We believe that the models used in the present study are useful to prove the fixation strength of the inserted screws. Lastly, the loading conditions do not perfectly replicate in vivo loads acting on the screw, as the present FE models do not account for the effect of cyclic loads. Although we evaluated the POS and screw-bone stiffness as objective variables representing the fixation strength of the pedicle screw, Law et al. reported the importance of caudocephalad cyclic loading in the mechanism of pedicle screw loosening. ${ }^{15}$ To simulate the real condition more precisely, further loading protocols are needed to elucidate the detailed biomechanical characteristics. In addition, it is unclear what level of stiffness is ideal for spinal fusion; therefore, more research with longterm clinical and radiological results is necessary.

\section{Conclusions}

This study has clarified the fixation strength using the CBT technique. The CBT has superior fixation strength of each individual screw and sufficient stiffness in flexion and extension loadings within a construct. The TT construct is superior to the CBT construct during lateral bending and axial rotation. These results should be beneficial to spine surgeons in the selection of operative methods.

\section{References}

1. Abumi K, Panjabi MM, Kramer KM, Duranceau J, Oxland T, Crisco JJ: Biomechanical evaluation of lumbar spinal stability after graded facetectomies. Spine (Phila Pa 1976) 15:1142-1147, 1990

2. Brodke DS, Bachus KN, Mohr RA, Nguyen BK: Segmental pedicle screw fixation or cross-links in multilevel lumbar constructs. a biomechanical analysis. Spine J 1:373-379, 2001

3. Bühler DW, Berlemann U, Oxland TR, Nolte LP: Moments and forces during pedicle screw insertion. In vitro and in vivo measurements. Spine (Phila Pa 1976) 23:1220-1228, 1998

4. Chao CK, Hsu CC, Wang JL, Lin J: Increasing bending strength and pullout strength in conical pedicle screws: biomechanical tests and finite element analyses. J Spinal Disord Tech 21:130-138, 2008

5. Chatzistergos PE, Sapkas G, Kourkoulis SK: The influence of the insertion technique on the pullout force of pedicle screws: an experimental study. Spine (Phila Pa 1976) 35:E332E337, 2010

6. Coe JD, Warden KE, Herzig MA, McAfee PC: Influence of bone mineral density on the fixation of thoracolumbar implants. A comparative study of transpedicular screws, laminar hooks, and spinous process wires. Spine (Phila Pa 1976) 15:902-907, 1990

7. Faizan A, Kiapour A, Kiapour AM, Goel VK: Biomechanical analysis of various footprints of transforaminal lumbar interbody fusion devices. J Spinal Disord Tech 27:E118E127, 2014

8. Halvorson TL, Kelley LA, Thomas KA, Whitecloud TS III, Cook SD: Effects of bone mineral density on pedicle screw fixation. Spine (Phila Pa 1976) 19:2415-2420, 1994

9. Hirano T, Hasegawa K, Takahashi HE, Uchiyama S, Hara T, Washio T, et al: Structural characteristics of the pedicle and its role in screw stability. Spine (Phila Pa 1976) 22:25042510,1997

10. Imai K, Ohnishi I, Bessho M, Nakamura K: Nonlinear finite element model predicts vertebral bone strength and fracture site. Spine (Phila Pa 1976) 31:1789-1794, 2006

11. Inceoğlu S, Montgomery WH Jr, St Clair S, McLain RF: Pedicle screw insertion angle and pullout strength: comparison of 2 proposed strategies. J Neurosurg Spine 14:670-676, 2011

12. Keyak JH, Rossi SA, Jones KA, Skinner HB: Prediction of femoral fracture load using automated finite element modeling. J Biomech 31:125-133, 1998

13. Krenn MH, Piotrowski WP, Penzkofer R, Augat P: Influence of thread design on pedicle screw fixation. Laboratory investigation. J Neurosurg Spine 9:90-95, 2008

14. Labrom RD, Tan JS, Reilly CW, Tredwell SJ, Fisher CG, Oxland TR: The effect of interbody cage positioning on lumbosacral vertebral endplate failure in compression. Spine (Phila Pa 1976) 30:E556-E561, 2005

15. Law M, Tencer AF, Anderson PA: Caudo-cephalad loading of pedicle screws: mechanisms of loosening and methods of augmentation. Spine (Phila Pa 1976) 18:2438-2443, 1993

16. Liebschner MA: Biomechanical considerations of animal models used in tissue engineering of bone. Biomaterials 25:1697-1714, 2004

17. Lim TH, Kim JG, Fujiwara A, Yoon TT, Lee SC, Ha JW, et al: Biomechanical evaluation of diagonal fixation in pedicle screw instrumentation. Spine (Phila Pa 1976) 26:24982503, 2001

18. Mahmoud A, Wakabayashi N, Takahashi H, Ohyama T: Deflection fatigue of Ti-6Al-7Nb, Co-Cr, and gold alloy cast clasps. J Prosthet Dent 93:183-188, 2005

19. Matsukawa K, Yato Y, Kato T, Imabayashi H, Asazuma T, Nemoto K: In vivo analysis of insertional torque during pedicle screwing using cortical bone trajectory technique. Spine (Phila Pa 1976) 39:E240-E245, 2014

20. Matsukawa K, Yato Y, Nemoto O, Imabayashi H, Asazuma T, Nemoto K: Morphometric measurement of cortical bone trajectory for lumbar pedicle screw insertion using computed tomography. J Spinal Disord Tech 26:E248-E253, 2013

21. Perez-Orribo L, Kalb S, Reyes PM, Chang SW, Crawford NR: Biomechanics of lumbar cortical screw-rod fixation 
versus pedicle screw-rod fixation with and without interbody support. Spine (Phila Pa 1976) 38:635-641, 2013

22. Santoni BG, Hynes RA, McGilvray KC, Rodriguez-Canessa G, Lyons AS, Henson MAW, et al: Cortical bone trajectory for lumbar pedicle screws. Spine J 9:366-373, 2009

23. Silva P, Rosa RC, Shimano AC, Defino HLA: Effect of pilot hole on biomechanical and in vivo pedicle screw-bone interface. Eur Spine J 22:1829-1836, 2013

24. Sterba W, Kim DG, Fyhrie DP, Yeni YN, Vaidya R: Biomechanical analysis of differing pedicle screw insertion angles. Clin Biomech (Bristol, Avon) 22:385-391, 2007

25. Tsitsopoulos PP, Serhan H, Voronov LI, Carandang G, Havey RM, Ghanayem AJ, et al: Would an anatomically shaped lumbar interbody cage provide better stability? An in vitro cadaveric biomechanical evaluation. J Spinal Disord Tech 25:E240-E244, 2012

26. Wahba GM, Bhatia N, Bui CNH, Lee KH, Lee TQ: Biomechanical evaluation of short-segment posterior instrumentation with and without crosslinks in a human cadaveric unstable thoracolumbar burst fracture model. Spine (Phila Pa 1976) 35:278-285, 2010

27. Weinstein JN, Spratt KF, Spengler D, Brick C, Reid S: Spinal pedicle fixation: reliability and validity of roentgenogrambased assessment and surgical factors on successful screw placement. Spine (Phila Pa 1976) 13:1012-1018, 1988

28. Wu SS, Edwards WT, Yuan HA: Stiffness between different directions of transpedicular screws and vertebra. Clin Biomech (Bristol, Avon) 13 (1 Suppl 1):S1-S8, 1998

29. Zander T, Rohlmann A, Klöckner C, Bergmann G: Influence of graded facetectomy and laminectomy on spinal biomechanics. Eur Spine J 12:427-434, 2003

30. Zindrick MR, Wiltse LL, Widell EH, Thomas JC, Holland WR, Field BT, et al: A biomechanical study of intrapeduncular screw fixation in the lumbosacral spine. Clin Orthop Relat Res (203):99-112, 1986

\section{Author Contributions}

Conception and design: Matsukawa, Yato, Imabayashi. Acquisition of data: Matsukawa. Analysis and interpretation of data: Matsukawa. Drafting the article: Matsukawa. Critically revising the article: Yato, Asazuma, Nemoto. Reviewed submitted version of manuscript: Yato, Imabayashi, Hosogane. Approved the final version of the manuscript on behalf of all authors: Matsukawa. Statistical analysis: Matsukawa. Administrative/technical/material support: Yato, Hosogane, Asazuma. Study supervision: Yato, Asazuma, Nemoto.

\section{Correspondence}

Keitaro Matsukawa, Department of Orthopaedic Surgery, National Defense Medical College, 3-2 Namiki, Tokorozawa, Saitama 359-8513, Japan. email: keitaro197897@ hotmail.com. 